\title{
Laboreal
}

Volume $2 \mathrm{~N}^{\circ} 1$ | 2006

Varia

\section{Luz, câmara, acção : orientações para a filmagem da actividade real de trabalho}

Luz, cámara, acción : orientaciones para la filmación de la actividad real de trabajo

Lumière, caméra, action: orientations pour le filmage de l'activité réelle de travail

Lights, camera, action : guidelines to the filming of real work activities

\section{Liliana Cunha, Rita Gil Mata e Fernanda Correia}

\section{OpenEdition}

\section{Journals}

\section{Edição electrónica}

URL: http://journals.openedition.org/laboreal/13609

DOI: $10.4000 /$ laboreal. 13609

ISSN: 1646-5237

\section{Editora}

Universidade do Porto

\section{Refêrencia eletrónica}

Liliana Cunha, Rita Gil Mata e Fernanda Correia, « Luz, câmara, acção : orientações para a filmagem da actividade real de trabalho », Laboreal [Online], Volume $2 \mathrm{~N}^{0} 1$ | 2006, posto online no dia 01 julho 2006, consultado o 10 outubro 2019. URL : http://journals.openedition.org/laboreal/13609 ; DOI : 10.4000/laboreal.13609

Este documento foi criado de forma automática no dia 10 outubro 2019. 


\section{Luz, câmara, acção : orientações para a filmagem da actividade real de trabalho}

Luz, cámara, acción : orientaciones para la filmación de la actividad real de trabajo

Lumière, caméra, action: orientations pour le filmage de l'activité réelle de travail

Lights, camera, action : guidelines to the filming of real work activities

Liliana Cunha, Rita Gil Mata e Fernanda Correia

\section{NOTA DO EDITOR}

Manuscrito recebido em : Março/2006

Aceite após peritagem em : Julho/2006

\section{A utilização do vídeo na aproximação ao real}

1 O recurso à gravação de imagens na análise da actividade de trabalho tem uma história relativamente recente. Aquando do surgimento da obra "Analyse du travail" de Ombredane e Faverge (1955), foi pedido à equipa destes autores a realização de um filme sobre análise do trabalho. É então neste contexto que surge a aplicação desta técnica com um fim específico, tratando-se na altura de difundir melhor as pesquisas desenvolvidas.

2 No entanto, este filme não teve tanto impacto como a obra escrita - apenas recentemente foi (re)descoberto e analisado. Ainda assim, utilizava-se pela primeira vez este procedimento para procurar uma maior aproximação ao que se passava em contexto real de trabalho. 
3 Paralelamente a esta ênfase da démarche ergonómica no real, também no cinema existe uma técnica específica, designada por "técnica do cinema directo", que nos anos 60 revelou ter uma grande influência na nova vaga de realizadores que surgiu na Europa. O objectivo consistia em filmar a realidade tal como ela aparecia, "fixá-la", fazer do cinema/vídeo um instrumento ao seu serviço, não havendo guiões nem cenários. É esta a época em que se dá o grande desenvolvimento dos documentários, das filmagens na rua, dos "directos", com gravação em tempo real da imagem e do som, não manipulando as situações e acontecimentos apresentados ao público - princípio que vem adequar-se à prossecução dos objectivos da ergonomia.

4 No âmbito da ergonomia, são fisiologistas os primeiros a utilizar este método, pretendendo explicitar em pormenor as posturas, gestos e movimentos do corpo humano. Lascaux (2005) relata uma investigação na qual dois fisiologistas incorporaram luzes de Natal em fatos de trabalho de operadores, filmando depois com o mínimo de luz possível, o que permitiu tirar conclusões sobre os movimentos precisos implicados em determinadas acções.

5 Desde estes primeiros momentos, as potencialidades da utilização do filme foram ampliadas, tanto mais com a evolução das possibilidades técnicas das câmaras, das técnicas e estratégias do filme e do vídeo e da própria difusão do meio audiovisual. As câmaras de filmar foram sendo tornadas mais leves e mais sensíveis, permitindo a filmagem em situações de reduzida iluminação ou mobilidade. Também a melhoria da película acabou por revolucionar as possibilidades oferecidas pela técnica de filmagem directa : esta viria a permitir captar o real, um real que então passou a incluir também tudo aquilo que permanecia ainda invisível a olho nu.

6 É sobre o importante papel da gravação vídeo como instrumento de observação e suporte à intervenção que nos debruçaremos seguidamente com mais pormenor.

\section{O filme ao serviço de uma abordagem compreensiva da actividade}

7 A utilização do filme ao nível da intervenção advém, então, do reconhecimento das suas potencialidades enquanto ponto de partida de alguns métodos de investigação/ intervenção e, mais recentemente, de formação. Por exemplo, através do método de autoconfrontação, em que o vídeo assume um papel determinante, é possível mostrar os elementos visíveis da actividade de trabalho, os quais podem depois servir de suporte para compreender outros elementos de que ela se reveste e que escapam à simples observação - como o significado das actividades impedidas ou contrariadas.

8 A imagem apenas permite, no entanto, ler uma das dimensões da actividade: à semelhança de um iceberg (Baratta, 1996), a filmagem apenas mostra a parte "emersa", visível da actividade. Para descobrir os sentidos e significados das estratégias postas em prática, é preciso aceder aos trabalhadores, que nos explicitam os motivos e as opções que os guiam.

De facto, uma das aplicações mais frequentes da filmagem consiste na sua utilização para o desenvolvimento de entrevistas com os trabalhadores, favorecendo a recolha das suas apreciações e comentários emitidos face às estratégias que desenvolvem na actividade. As imagens contribuem para uma reflexão e um questionamento sobre os modos operatórios desenvolvidos em determinadas condições de trabalho, 
considerando que os saberes-fazer dos trabalhadores nem sempre são conscientes, o que acaba por dificultar a sua verbalização através de um simples questionamento directo (Baratta \& Berthet, 2000). O confronto dos trabalhadores com as imagens do próprio exercício da actividade permite ainda desencadear o debate sobre os acontecimentos ou sequências que consideram mais significativas e contribui para atribuir um outro valor à palavra : um valor demonstrativo (idem) da eventualidade de considerar outras opções em termos de organização do trabalho, propostas a partir da experiência concreta dos trabalhadores.

10 O filme pode então contribuir para o processo de transformação das situações de trabalho ao desencadear a produção de conhecimentos fundamentais para a proposta de novas soluções, de medidas preventivas, de modificações ao nível da organização do trabalho. A partir da filmagem podem ser colocados em evidência os elementos concretos, tangíveis, demonstrativos da actividade, que funcionarão como argumentos base, úteis para os investigadores, preventores, conceptores e actores da empresa na modificação das situações de trabalho.

11 Com efeito, a utilização do filme facilita o desenvolvimento de metodologias de observação diferidas. Pode ainda sedimentar vários traços das mesmas actividades, a fim de que as pessoas filmadas, cuja actividade estamos a analisar, possam passar do estatuto de observados ao de observadores (Clot, 2000), coactores e também co-autores na produção dos dados recolhidos. A prática do filme no âmbito da ergonomia, constitui uma ajuda no plano de instrumentalização ao nível da análise da actividade mas facilita também o contacto, reforça a colaboração e enriquece a reflexão em comum com os trabalhadores, afirmando-se assim como instrumento de comunicação.

o recurso ao vídeo tem-se revelado também uma mais-valia importante ao nível do desenvolvimento de diferentes modelos de formação orientados para a transformação do trabalho pelos seus actores, a partir da sua análise. Alguns estudos recentes em Portugal (Santos, 2004), têm demonstrado como a tendência dominante em termos de formação profissional continua a ser a de associar a formação a intervenções desarticuladas dos contextos reais de trabalho, com conteúdos abstractos ou dirigidos ao trabalho prescrito (sem envolvimento dos formandos e dos seus representantes) e com base em programas padronizados, maioritariamente concebidos por consultores externos, frequentemente alheados das actividades reais de trabalho daqueles a quem essa formação se dirige.

13 É precisamente a concepção de saber que subjaz a este tipo de práticas que tem vindo a ser discutida por diversos autores (Maggi, 1996 ; Jobert, 2000), e cuja proposta de uma outra abordagem da formação é, em grande parte, enriquecida pela integração do vídeo na análise.

14 Estes métodos, de que a auto-análise ergonómica (Six \& Carlin, 1993) e a autoconfrontação cruzada (Clot et al., 2000) constituem exemplos paradigmáticos, visam suscitar e desenvolver um processo de análise pelo formando, que permita a reconstrução da sua actividade e da sua situação de trabalho por si mesmo, objectivos que são facilitados porque a utilização do vídeo, que constitui uma base integrante desses métodos, favorece e auxilia o regresso mental à actividade real de trabalho. 


\subsection{O papel do vídeo em clínica da actividade : encontro e confronto entre o discurso e o trabalho real}

O método clínico tal como enunciado por Clot e Leplat (2005) enceta duas facetas : uma centrada sobre o conhecimento da actividade (prefigurando um objectivo claramente epistémico, orientado para o conhecimento de uma situação de trabalho) e a outra sobre a transformação dessa actividade (encerrando, neste caso, um objectivo de resposta a uma situação particular e, consequentemente, também um objectivo epistémico, pelas implicações que esta transformação acaba por ter no conhecimento que já detínhamos sobre a actividade). Neste caso, e se a "pesquisa assenta sobre o desenvolvimento da actividade e não somente sobre o seu funcionamento, não basta compreender para transformar, mas também transformar para compreender" (Clot, 2000, p. 137, tradução livre).

Clot fala-nos, pois, de uma clínica da actividade (1999), considerando a proximidade que a análise do trabalho tem com o método clínico (Clot \& Leplat, 2005). Nesta abordagem, o método de autoconfrontação é talvez o melhor exemplo do estatuto do vídeo como ponto de partida para a criação de condições favoráveis ao desenvolvimento de uma outra perspectiva sobre a actividade e sobre a sua transformação. É "através da mediação que a utilização do vídeo possibilita, que se inscreve num processo de coprodução do conhecimento sobre o objecto de pesquisa" (Béguin, 1996, p. 41 tradução livre).

O método de auto-confrontação integra, em linhas gerais, o princípio do confronto com a actividade do próprio (no caso da autoconfrontação simples) ou do outro (um par "expert", no caso da autoconfrontação cruzada), como recurso metodológico na análise das situações de trabalho (Clot et al., 2000 ; Vieira, 2004).

O objectivo consiste em compreender o que se faz, através da observação da actividade (de sequências da actividade filmadas e apresentadas em vídeo aos trabalhadores) em confronto com o que se pensa que se faz nessa situação. 0 pensamento acerca do que se faz realiza-se nos comentários emitidos face às situações de trabalho observadas.

Este confronto visa desenvolver um processo de análise pelo trabalhador, capaz de permitir-lhe reconstruir a sua actividade por si mesmo, recorrendo a processos mentais semelhantes aos da análise guiada (Six \& Carlin, 1993), mas auxiliando o regresso mental à actividade de trabalho, neste caso, com o recurso a imagens vídeo.

Trata-se de um método centrado numa perspectiva reflexiva, uma vez que se propõe ao trabalhador um exercício de reflexão sobre aquela que é a actividade habitual de trabalho (sua ou de um par "expert" no mesmo domínio), encontro este que é também ele registado em vídeo.

21 Falamos de autoconfrontação simples na situação em que o trabalhador é confrontado com uma sequência de imagens relativas à sua própria actividade. Os comentários que realiza são, neste caso, dirigidos ao formador ou investigador.

No entanto, o destinatário destes comentários muda quando nos reportamos à autoconfrontação cruzada e esta mudança não é isenta de significado para o trabalhador (Clot, 2000), sendo exemplo disso o facto de o esclarecimento sobre os detalhes da actividade se revestir de particularidades, dependendo do interlocutor.

A autoconfrontação cruzada consiste, então, na criação de uma situação na qual, sobre uma mesma actividade filmada, cada trabalhador comenta a actividade dos outros. Ou 
seja, o recurso ao registo de som e imagem da actividade serve de base aos comentários dos trabalhadores.

A confrontação com modos operatórios diferenciados favorece a explicitação das acções (ênfase em "como se faz", mais do que em "porque se faz") e o enriquecimento da actividade "resultante" do processo de análise (Clot, 2000).

Isto significa que, para que a análise da actividade, através do confronto com imagens vídeo de uma sequência de trabalho determinada, se possa revelar um bom instrumento de formação, ou seja, (...) "na condição de se tornar um instrumento de transformação da experiência" (Clot, 2000, p. 154, tradução livre) é fundamental que se tenha igualmente em atenção as imagens da actividade $e$ as verbalizações correspondentes. Se por um lado falamos de qualidade das imagens filmadas, por outro lado, o registo áudio não pode ser considerado menos importante. Aliás, é pela atenção atribuída a estes dois elementos que poderemos assegurar a indispensável sincronização entre as imagens e os comentários, entre a experiência vivida e a experiência reflectida.

Os registos vídeo auxiliam a condução do processo de análise e co-análise, pois é em função destes que se constrói o discurso, tornando consciente a actividade de trabalho e os seus constrangimentos, num processo de construção da "(...) imagem sobre a imagem, a palavra sobre a imagem, a palavra sobre a palavra (...)" (Lacoste, 1996, p. 9, tradução livre).

\subsubsection{Os diferentes momentos do método de autoconfrontação}

O método de autoconfrontação integra diferentes fases, em que os trabalhadores protagonistas das situações em análise, à partida, seriam, sucessivamente, confrontados com a sua actividade e posteriormente com a actividade dos outros.

Segundo Clot, podemos falar de três importantes etapas na autoconfrontação, intercorrelacionadas: "o que se faz, o que se diz do que se faz e o que se faz do que se diz" (Clot \& Leplat, 2005, p. 135).

o sentido subjectivo que cada um encontra para adaptar o trabalho prescrito à realidade de trabalho ganha aqui um estatuto privilegiado, comparativamente com a descrição objectiva do que se faz. Ao fazê-lo "muda-se o estatuto do vivido : de objecto de análise, o vivido deve tornar-se meio para viver outras vidas" (Clot, 2000, p. 154, tradução livre).

Podemos então resumir o procedimento associado a este método em três grandes momentos :

1. Constituição do grupo de análise: fase de observação no terreno, conduzida pelos investigadores com o objectivo de permitir a elaboração de uma representação partilhada com os trabalhadores sobre a sua situação de trabalho (Clot, 2000). Este trabalho de análise da actividade irá permitir escolher as situações de trabalho que constituirão o objecto de análise, em concordância com os critérios especificados por quem fez o pedido de análise.

2. O momento de autoconfrontação propriamente dito: é nesta fase que os trabalhadores esclarecem para o outro (formador, investigador ou colega de trabalho) a sua actividade, através de comentários às imagens observadas. Tem início com a construção de documentos vídeo que servirão de base às auto-confrontações simples (um sujeito / investigador/ as imagens recolhidas para este sujeito) e cruzadas (dois sujeitos / investigador / as imagens 
recolhidas para estes sujeitos) em função dos trabalhadores e situações de trabalho escolhidas no primeiro momento (Clot, 2000).

3. Extensão do trabalho de análise ao colectivo profissional : finalmente faz-se a devolução da análise efectuada pelos trabalhadores para se promover um diálogo no colectivo que retome as questões da actividade - as regras, as normas e possibilidades de intervenção, que por eles serão sujeitas a validação. Todavia, não se trata de uma restituição da experiência adquirida : "a análise do trabalho confere um valor acrescentado à actividade descrita e é a este título que ela pode ser formadora” (Clot, 2000, p. 145, tradução livre). intervenção colectivo "pois só ele é susceptível de garantir o acompanhamento posterior dos trabalhadores no reconhecimento e seguimento do trabalho realizado indo contra os riscos de responsabilização individual" (Lacomblez, 2002).

gças ao movimento entre actividade, representação da actividade e "actualização dos feitos com os ditos", promovido pelo recurso à filmagem (Vieira, 2004, p. 223), que se contribui para a tomada de consciência da actividade e dos seus determinantes e se facilita a apropriação do processo de análise do trabalho (Clot, 2000 ; Santos 2004).

A utilização do vídeo é finalmente assumida como um instrumento privilegiado para aprender a observar, para desenvolver competências de leitura e interpretação das situações de trabalho, enfim, para servir mais como suporte à observação do que como meio para "mostrar" a actividade, ao permitir que o trabalhador consiga a distância necessária para adquirir um outro ponto de vista sobre a sua actividade.

Nesta perspectiva, o adulto é reconhecido como detentor de uma experiência que integra melhor no seu comportamento, porque é ele próprio quem a reconstrói. Através do registo vídeo, é então possível aproximarmo-nos dos saberes-fazer dos trabalhadores e das estratégias que colocam em prática, com o propósito de os vermos discutidos por eles mesmos.

Finalmente, é graças a ele que se torna possível o confronto do trabalhador com a sua actividade tal como ela é, correspondendo à conjunção de condições favoráveis à explicitação das representações que constroem da sua própria actividade.

Neste sentido, além de se constituir como um instrumento ao serviço da formação, contribui ainda para a afirmação de uma outra concepção de formação - a que decorre do pressuposto de que os trabalhadores são possuidores de uma "inteligência prática" (ou seja, de conhecimentos que se elaboram na acção e são mobilizados nessa mesma acção), construída ao longo da sua experiência profissional, pelo confronto com diferentes tipos de situações e que passa a constituir a matéria-prima da formação.

A partir de um dispositivo comum de trabalho, a actividade real de trabalho, os trabalhadores e os investigadores podem então começar a pensar colectivamente o trabalho para o reorganizar.

E se de facto o vídeo pode contribuir para o desenvolvimento de uma abordagem compreensiva das situações de trabalho analisadas, para a valorização do discurso dos trabalhadores e ênfase no significado que atribuem a determinadas decisões, a sua utilização exige uma atenção particular sobre as condições em que terá lugar e o compromisso de uma interacção permanente entre a equipa de investigação, os trabalhadores e as especificidades inerentes à actividade e ao contexto onde ela é exercida. 


\section{Estratégias de realização na autoconfrontação}

39 O reconhecimento das vantagens da utilização do vídeo implica que se atente sobre um leque de condições, que devem ser tidas em conta em diferentes momentos associados a este método, orientados pela utilização do vídeo, tal como pode ser analisado através da sistematização que apresentamos de seguida.

40 A discussão acerca das estratégias de realização depende sem-pre dos objectivos da análise, a cada momento. Assim sendo parece-nos pertinente considerar, simultaneamente, duas fases no método de autoconfrontação :

1. a filmagem de sequências da actividade que constituirão o objecto de análise pelos trabalhadores e que servirão de base aos comentários que irão tecer ;

2. a filmagem da entrevista de autoconfrontação (assegurando a sincronização entre os comentários e as imagens de referência às verbalizações).

41 As indicações técnicas que apresentaremos em seguida serão divididas em função do momento de aplicação: antes, durante ou depois da filmagem, sendo consideradas transversais à maioria das situações que se pretende filmar. No entanto, e uma vez que as duas fases acima explicitadas encerram algumas particularidades técnicas, faremos menção a esses cuidados específicos ao longo do texto.

\subsection{A filmagem de sequências da actividade profissional}

42 A opção pela utilização do vídeo no decurso da démarche ergonómica merece algumas considerações. Esta técnica não é panaceia (Béguin, 1996) para uma análise exaustiva da actividade. A escolha de uma metodologia, seja ela qual for, deve traduzirse numa adequação dos meios aos objectivos de estudo e depender do contexto específico de investigação, do pedido formulado e dos objectivos que lhe subjazem.

Assim, o registo de imagens vídeo parece fazer sentido quando tiver já sido elaborado um pré-diagnóstico da situação e com o objectivo específico de usar as imagens como suporte a outro tipo de metodologias (como a autoconfrontação), pretendendose ir para além das imagens, para o significado das opções assumidas no trabalho. Na verdade, “(...) a imagem da acção de trabalho produz efectivamente sentido, mas não no-lo diz (...)" (Baratta, 1996, p. 94, tradução livre). Só conhecendo o contexto, registando os primeiros contactos com os trabalhadores no terreno e depois da constituição de um colectivo - que irá ser determinante na construção de um primeiro diagnóstico da situação-problema - é que se poderá decidir se a filmagem será ou não uma técnica a privilegiar na investigação em curso. No caso afirmativo, deve então atentar-se a outros factores, como : a definição das imagens a recolher, pretendendo-se que permitam o desenvolvimento de análises posteriores, ou de metodologias que favoreçam uma outra compreensão do dados já disponíveis a partir das primeiras observações e contactos com diferentes interlocutores; ou o facto de a própria realização da actividade permitir ou não a possibilidade de captar imagens de qualidade do trabalhador, do seu posto de trabalho, das tarefas que realiza. 


\section{Fase I : Preparação da filmagem}

\section{Negociação com trabalhadores e direcção da empresa}

A partir do momento em que é tomada a decisão de recorrer ao uso da captação de imagens vídeo como instrumento de recolha de dados que sirvam de suporte ao desenvolvimento da investigação, inicia-se um processo que se reveste de cuidados e atenções, para que o seu uso seja o mais proveitoso possível.

De facto, a introdução de uma câmara de filmar nos contextos de trabalho deve ser feita de forma progressiva e cautelosa, sem que se verifique a sua imposição, o que poderia comprometer seriamente os resultados do estudo. A câmara é, sempre, no primeiro impacto, um elemento estranho, que carrega em si um conjunto de simbolismos que é importante "dessacralizar" (Lallier, 1996, p. 84), esclarecendo, nomeadamente, que não é pretendido que assuma o papel de controlo do que os trabalhadores fazem ou como fazem.

Um dos primeiros aspectos a ter em conta diz respeito à forma como se propõe a gravação da actividade de trabalho, quer à direcção da empresa onde se pretende efectuar o estudo, quer aos próprios trabalhadores. Nesta primeira fase é fundamental reunir o acordo da direcção da empresa e dos trabalhadores relativamente à utilização deste tipo de metodologia. A decisão da direcção torna-se, efectivamente, determinante para a realização do registo vídeo, na medida em que tem o poder de autorizar ou interditar este tipo de prática, bem como pode permitir que os trabalhadores participem na filmagem. Sem esta garantia, a aproximação às pessoas, que constitui uma das condições basilares para a filmagem e para a análise da actividade de trabalho, fica comprometida.

Aquando desta fase de negociação com a direç̧ão da empresa e com os trabalhadores é conveniente explicitar vários factores :

- quando, onde e como se prevê realizar as filmagens : a presença do investigador no local de trabalho deve ser a mais discreta possível, devido às interferências que esta - e especialmente a da câmara - poderão suscitar. A assistência de chefias superiores no momento da filmagem também deve ser precavida (excepto, obviamente, nos casos em que esta é habitual na situação de trabalho), já que poderia constranger ainda mais os trabalhadores. A participação dos trabalhadores será fundamental na escolha das situações que irão constituir objecto de análise, pelo que devem ser definidas garantias que a estes poderão ser dadas e atentar para que estas não sejam nunca violadas. Este aspecto ganha, no entanto, particular relevância nos momentos de entrevista de autoconfrontação. Estas devem ser realizadas num ambiente calmo, sem interrupções, no qual esteja explícito o ambiente de confidencialidade e anonimato, criando uma espécie de "contrato moral" entre o que entrevista, o que filma e o que fala (Lallier, 1996, p. 93).

- como será apresentada a montagem final do filme : e a quem, em que condições, sob que formas. O conhecimento concreto dos propósitos da investigação e dos usos que poderão advir das conclusões desta, é muitas vezes motivo de desconfiança e de retraimento dos trabalhadores, até da própria direcção. Nesta altura é importante clarificar que a filmagem a ser realizada não é para a "televisão", mas sim um trabalho com preocupações científicas subjacentes que pretende contribuir para a melhoria das situações de trabalho. No entanto, a construção de um vídeo remete directamente para uma assumpção de difusão mediática, que deve ser previamente definida, acordada e transmitida a todos os intervenientes. 
obstante, mesmo que se verifique a aceitação por parte da empresa e ainda que estejam reunidas e sejam previstas todas as condições necessárias e imprescindíveis, não se poderão realizar as filmagens da actividade de trabalho sem o aval dos trabalhadores. A colaboração e a adesão destes aos estudos que contemplam a realização das filmagens só são possíveis na medida em que o próprio investigador vai ganhando a confiança dos trabalhadores. De acordo com o pressuposto de que a utilização desta técnica apenas surgirá num momento avançado da investigação e em articulação entre momentos de presença no terreno e momentos de filmagem (Ganne \& Penard, 1996), esta relação de proximidade e confiança deve ser trabalhada à partida. Por um lado, a presença de câmaras provoca, frequentemente, uma sensação de desconfiança e desconforto na maioria dos indivíduos, a qual é preciso gerir - e aqui a clareza na definição de objectivos poderá trazer segurança - por outro lado, a participação activa destes é um requisito essencial para o prosseguimento da filmagem. o envolvimento dos trabalhadores no processo é fundamental para a passagem de observados a observadores (Clot, 2000), e para que, no momento de entrevista de autoconfrontação, o esclarecimento para o outro - neste caso, o investigador - seja facilitado. É nesta fase que o diálogo entre investigadores e trabalhadores poderá levar à construção de uma concepção partilhada da situação de pesquisa.

o estabelecimento desta relação participativa não se deve estender apenas aos trabalhadores cuja actividade de trabalho irá ser filmada. Importa sim, mobilizar ainda um colectivo que irá acompanhar o trabalho: as decisões finais e intermédias serão aí definidas progressivamente e avaliadas em conjunto, de acordo com as possibilidades e os objectivos associados ao estudo.

50 Uma vez estabelecido o acordo para a filmagem, há ainda uma série de considerações que devem ser integradas no planeamento da filmagem, nomeadamente, as condições físicas e materiais que a sustentarão.

\section{0 estudo prévio do local de filmagem}

51 Inicialmente deve-se ter em atenção o(s) local(ais) onde terá lugar a filmagem, ou seja, é fulcral que sejam previamente estudados, a fim de se evitar o confronto com determinados imprevistos no momento da filmagem. Na verdade, o conhecimento do local de trabalho, dos obstáculos que lá se encontram, das potencialidades que este comporta ou das possibilidades técnicas ao nível de luz e som, fazem parte integrante das tarefas a realizar nesta fase. Devem ser realizados ensaios, através de pequenas sequências de filmagem, no sentido de perceber quais as opções que melhor se adequam aos objectivos definidos e evitar possíveis constrangimentos.

\section{Disposição espacial}

O conhecimento pormenorizado da posição espacial dos diferentes elementos torna-se essencial. A posição dos trabalhadores, dos equipamentos, dos fios, os trajectos habituais de cada operador no decurso da sua actividade, são indicadores que irão estruturar a marcação do lugar de filmagem. Podemos considerar, por exemplo, que filmar de um determinado ângulo será uma boa opção, pois teremos uma imagem que abarca tanto o trabalhador como o computador em que ele trabalha, e não sinalizarmos que a passagem de um outro trabalhador por aquele local nos cortará a visibilidade. Por outro lado, poderemos estar a considerar mover a câmara de um ponto para outro e 
não nos apercebermos que entraremos em conflito com uma mesa, uma cadeira ou com um grupo de fios. Aliás, é devido a este tipo de situações que Lascaux (2005) aconselha a realização da filmagem em pares, na medida em que o investigador que não está a operar com a câmara pode estar mais atento a estes obstáculos e orientar o colega.

A disposição espacial ganha particular relevância nos momentos de entrevista de autoconfrontação, já que vários elementos estarão presentes e a facilidade na visualização das imagens, bem como a sua compreensão, devem ser asseguradas. No caso da entrevista de autoconfrontação simples e considerando que tem de ser prevista a presença de um trabalhador, de um investigador e ainda da televisão que mostrará as filmagens a comentar, deve estar certificado o enquadramento de todos estes elementos na visualização da imagem a filmar (ou, caso não seja possível, a existência de mais que uma câmara de modo a filmar simultaneamente as imagens que a televisão mostra, as reacções do trabalhador perante estas, os seus comentários e as questões colocadas pelo investigador). Para confirmar o enquadramento correcto de todos estes elementos o investigador poderá fazer ensaios com colegas, no local definido para as entrevistas. No caso da entrevista de autoconfrontação cruzada, o cenário será semelhante, já que, apesar de estarem presentes dois trabalhadores, será prescindível a filmagem do investigador. Aqui torna-se mais interessante filmar a interacção entre os dois profissionais, sendo que o registo das questões colocadas pelo investigador está assegurado a nível sonoro (ainda que não necessariamente visível na imagem).

\section{A iluminação e o som}

A iluminação e o ruído constituem dois parâmetros determinantes para a qualidade da filmagem, razão pela qual devem ser cuidadosamente previstos, quaisquer que sejam as situações a filmar.

Relativamente à iluminação há que ter em conta a necessidade de uma boa luminosidade do espaço. Uma das formas de colmatar a não existência desta condição pode traduzir-se pela utilização de uma fonte de luz portátil que, virada para o tecto, recaia sobre a situação a filmar, produzindo-se uma luz indirecta que favorece a qualidade da filmagem. No entanto, torna-se necessário reflectir acerca do posicionamento do foco de luz em momentos de filmagem da situação de trabalho, na medida em que este não deve perturbar o trabalhador no exercício da sua actividade, nem interferir com quaisquer equipamentos com que este trabalhe.

No que diz respeito ao som, devemos estudar o nível de ruído da atmosfera de trabalho. Se a filmagem decorre numa atmosfera com um ruído de fundo pouco significativo, a utilização do próprio microfone da câmara será, em princípio, suficiente. De forma semelhante ao que acontece com a objectiva da câmara, o microfone funciona de modo selectivo, ou seja, não capta todas as fontes de som provenientes de todas as direcções. Por esta razão e segundo Lascaux (2005), a melhor opção ao nível do som consiste em utilizar um microfone semi-direccional, a ser colocado na câmara de filmar. 0 tamanho do microfone também deve ser escolhido em resultado do tipo de situação que pretendemos filmar. $\mathrm{O}$ microfone canhão, por exemplo, apenas deve ser usado em situações específicas, quando a filmagem é realizada a grande distância - poderá ser útil em contextos de alta segurança, em que o investigador não tem autorização para se aproximar da zona de actividade. De facto, este tipo de sistema tem um efeito de alvo muito semelhante ao de uma arma (daí a sua designação), pelo que deve estar muito bem alinhado para que se verifique a captação de som. Existe ainda o microfone "UHF" 
(sem fios) que consiste em dois módulos separados: um que é transportado pelo trabalhador no bolso ou na lapela e outro que pode ser acoplado à câmara. Este sistema tem, então, a vantagem de permitir tanto ao trabalhador como à pessoa que está a filmar uma maior liberdade de movimentos, podendo ambos circular sem qualquer impedimento e sem comprometer a gravação do som.

$\mathrm{Na}$ gravação das entrevistas de autoconfrontação, ainda que estas se prevejam num local calmo, a qualidade do som deve ser testada, já que haverá simultaneamente o som das imagens mostradas na televisão, das verbalizações dos trabalhadores e do investigador. Uma solução poderá ser o posicionamento central de um microfone que, ligado à câmara, capte em estéreo o ambiente da sala.

\section{Escolha e organização do material}

Outra tarefa importante e que se enquadra nesta fase preparatória prende-se com a escolha e organização do material a ser utilizado, de acordo com as circunstâncias que encontramos no terreno. Entre os materiais a privilegiar na filmagem devemos ter em consideração as vantagens e desvantagens associadas a cada tipo de câmara.

Por exemplo, as pequenas câmaras digitais têm um campo visual bastante reduzido, o que acaba por dificultar a captação de pormenores associados, nomeadamente, com os gestos dos trabalhadores, bem como inviabilizar a possibilidade de obter a filmagem em simultâneo de dois trabalhadores (mantendo fixa a filmagem de um deles e obtendo um segundo plano de um outro trabalhador, que pode, por exemplo, estar a realizar a mesma tarefa). Uma das formas de contornar esta situação pode ser através da adaptação à câmara de uma lente grande ângulo, capaz de permitir um maior ângulo de captação de imagem e filmar todo o espaço envolvente. No caso de não haver a possibilidade de conseguirmos uma lente de grande ângulo, teremos que nos movimentar constantemente, o que pode interferir na captação de uma boa imagem. A lente grande ângulo pode também ser uma solução para a dificuldade de enquadramento de todos os elementos presentes nas entrevistas de autoconfrontação. Assim, dado que o campo de visão é alargado, possibilitará, no mesmo enquadramento, a captação do(s) trabalhadores/investigador/televisão (de acordo com o tipo de entrevista de autoconfrontação), o que facilitará o posterior visionamento e garantirá a relação temporal entre as imagens mostradas na televisão e os comentários dos trabalhadores às mesmas.

Da sistematização de todos os elementos anteriores e da observação dos pequenos ensaios realizados nos momentos de deslocação ao local da filmagem para estudo prévio, deverá ser possível compor um guião de filmagem. Este deverá prever as principais marcações (lugares escolhidos para fixar a câmara), os trajectos a realizar, os constrangimentos específicos a levar em conta. Não se pretende, no entanto, confinar as possibilidades da filmagem ou ambicionar prever todas as potencialidades em todos os momentos - antes prever constrangimentos e permitir ao investigador orientar a sua actuação em função dos objectivos do estudo.

61 Finalmente, reforçamos uma vez mais a importância de, antes da filmagem propriamente dita, experimentar as várias funções da câmara, no sentido de obter uma boa capacidade de manipulação. Não se pode aprender a utilizar a câmara na véspera da filmagem. É conveniente já ter filmado, feito experiências, realizando, por exemplo, vídeos caseiros, o que ajuda a adaptar e aprender a lidar com a câmara. 


\section{Fase II : Realização da filmagem}

Uma vez cumpridos os pré-requisitos especificados na primeira fase, surge o momento da filmagem. Nesta etapa da gravação em vídeo, e antes de ir para o terreno, é pertinente confirmar se estamos munidos de todo o material necessário. É fundamental imprimir um carácter rigoroso a esta fase de preparação : é indispensável a verificação das baterias (confirmar se estão bem carregadas), averiguar se a câmara funciona em perfeitas condições, ligar o microfone e fazer ensaio de som para testar a sua qualidade.

É essencial garantir que a câmara está em condições para iniciarmos a filmagem no imediato, uma vez que o momento da filmagem pode antecipar-se : é conveniente ter mais do que uma bateria disponível, todas devidamente carregadas, estando uma delas já colocada na câmara. Do mesmo modo, deve estar assegurado o suporte para registo das imagens (seja este através de cassetes, DVD ou cartões de memória), estando a câmara já provida deste suporte antes do momento da filmagem. Todos os equipamentos suplementares devem ser revistos e verificados, na tentativa de prevenir perturbações no momento da filmagem.

\section{Os planos de filmagem}

Durante a filmagem podemos fazer uma série de opções concernentes ao que pretendemos focar.

Podemos privilegiar a "técnica do plano de sequência" (Lascaux, 2005) - não é suspensa a filmagem, construindo então um longo plano contínuo, sem cortes, que poderá ir até vários minutos, no qual o tempo filmado corresponde exactamente ao tempo real. Nesta situação não há interrupções nem mudança do plano visualizado, pelo que a câmara recolhe todas as imagens associadas à realidade do tempo decorrido - ricas em detalhes e indícios que poderão orientar análises posteriores. Podemos ainda iniciar a filmagem com algum distanciamento relativamente aos alvos a focar e, progressivamente, irmo-nos aproximando. Esta técnica de realização (de uma aproximação progressiva ao trabalhador) pode ser importante na filmagem de sequências da actividade de trabalho para transmitir segurança à pessoa que está a ser filmada, levando a que ela própria se sinta mais confortável com esta situação de gravação e, consequentemente, que realize a actividade de trabalho da forma mais habitual possível.

Para além disto, podemos referir que o plano pode ser medido em termos de tempo ou duração (planos curtos ou planos longos de filmagem), assim como podemos ainda fazer a distinção entre planos fixos e planos móveis.

No que concerne aos planos fixos a imagem a ser captada está fixa, não havendo qualquer movimentação da câmara. Esta opção será indicada ao verificar-se a existência de várias deslocações por parte do trabalhador, pelo que se torna conveniente escolher o melhor local para captar o que se passa na situação de trabalho em análise - uma visão mais abrangente que englobe deslocações do trabalhador dentro do mesmo plano. Neste quadro, o zoom permite a passagem de um plano fixo para um outro plano fixo (reenquadramento). Porém, embora o zoom permita uma maior aproximação aos detalhes envolvidos no desenvolvimento da actividade, o seu uso deve ser moderado, a fim de evitar mudanças bruscas na sequência de imagens apresentadas, o que pode criar confusão e empobrece as vantagens do plano fixo. 
68 A opção por um plano móvel (em movimento) relaciona-se, por outro lado, com a movimentação da imagem, quer esta corresponda ou não a uma movimentação real do investigador. Ao nível dos planos de mobilidade podemos encontrar os movimentos de câmara designados por "panorâmico" e por "travelling” (Lascaux, 2005).

O primeiro consiste numa rotação da câmara sobre o seu próprio eixo - esta está fixa, fazendo um movimento dentro do mesmo ângulo, como um "varrimento", o que facilita a observação de uma série de acções num mesmo espaço, pela mudança do campo visual. No movimento panorâmico, e ao contrário do que acontece no travelling, a câmara não sai do lugar, fica presa no tripé fazendo um movimento de 360 graus para a direita ou para a esquerda, imitando o olhar quando giramos a cabeça. Quando assistimos a um filme, temos oportunidade de reparar que muitas vezes este começa com uma panorâmica, pois com esse movimento, o realizador tem a possibilidade de mostrar ao espectador o lugar ou o espaço onde vai acontecer a história. Não obstante, e dependendo das situações, pode ser interessante tentar o efeito contrário : conjugar a visão panorâmica com a função zoom, ou seja, começar um movimento de filmagem e ir alargando-o ou estreitando-o.

70 O travelling, por seu turno, está presente em todos os momentos de deslocação, horizontal ou vertical, do posicionamento da câmara e, consequentemente, do investigador. Este movimento confere maior mobilidade às cenas. Neste caso é exigida particular atenção: temos de nos deslocar com cuidado, para evitar a construção de uma imagem irregular e trémula. Segundo Lascaux (2005), a posição mais adequada da câmara será ao nível da cintura, tendo o ecrã de visualização da máquina voltado para o investigador, para que este possa ir acompanhando o que está a gravar. Nesta situação torna-se especialmente produtiva a existência do outro investigador a colaborar na filmagem - este poderá auxiliar na deslocação, orientando e prevenindo, quer para possíveis obstáculos, quer para situações que estejam a acontecer fora do ângulo de captação da câmara e cujo interesse é notório.

71 Como síntese podemos referir que a escolha dos ângulos e dos enquadramentos da filmagem deve obedecer aos seguintes critérios: possibilitar a visibilidade da actividade; permitir a continuidade das filmagens (planos de sequência longos e descritivos); e, finalmente, proporcionar a grande mobilidade da câmara e a sua reactividade, de modo a permanecer bastante centrada nos protagonistas da acção, nos seus gestos, movimentos e verbalizações.

\section{0 papel do investigador}

72 Da mesma forma que as condições em que a filmagem tem lugar devem ser alvo de atenção, a postura assumida pelo investigador pode ser determinante nos resultados obtidos através da filmagem. Lascaux (2005), afirma que é essencial manter uma postura tranquila, profissional e não deixar transparecer uma possível inabilidade ou falta de experiência no manuseamento do equipamento, o que poderia causar perturbação nos trabalhadores. Conscientes de que a presença de uma pessoa que não faz parte do colectivo de trabalho pode interferir na actividade, é fundamental salvaguardar que esta se mantenha discreta.

73 De facto é possível afirmar que tudo o que acontece durante a concepção e a preparação da filmagem é útil ao filme. Não existem casualidades ou elementos de interesse menor não há condições ideais para a realização de um filme, mas serão, em última análise, 
elas que permitirão fazer o filme tal como é. Fazer um filme não é tentar adaptar a realidade a ideias préconcebidas, mas é sim estar pronto para responder/reagir a tudo o que possa acontecer, já que tudo contribui para a construção do seu produto final.

o momento da filmagem é circunscrito no tempo, captando e retendo o instante que passa. É graças ao vídeo que o mantemos em memória e o podemos rever para dele partir para a compreensão de algumas especificidades da actividade.

\section{A filmagem do trabalho na análise da actividade : potencialidades e limitações}

75 Explicitadas que estão as principais estratégias e técnicas necessárias para recorrer à gravação de imagens vídeo na autoconfrontação, cabe agora referir o modo como poderão ser utilizados os resultados que advêm destas captações.

76 A nível técnico, este material poderá ser útil para reflectir sobre inúmeras características da actividade dos trabalhadores, ora numa perspectiva mais quantitativa de expressão da actividade, ora numa abordagem de carácter mais qualitativo. De acordo com estes objectivos, a selecção das sequências da actividade a filmar ou as imagens filmadas irá ser, também, diferente.

77 No primeiro caso, será possível, por exemplo, avaliar as deslocações realizadas pelo trabalhador por dia, num determinado espaço, ou a carga total que desloca, em determinada unidade de tempo, ou ainda o número de vezes com que utiliza um equipamento específico. A potencialidade da visão das imagens ao ralenti volta a ser importante nesta etapa : por exemplo, analisar com exactidão qual o ângulo formado pelos braços do operador em determinada tarefa específica e retirar daí conclusões sobre a carga e as exigências posturais colocadas ao trabalhador. As análises possíveis são inúmeras, de acordo com os constrangimentos que analisamos, e daqueles que aparecerão indubitavelmente, ainda que no início não tenham sido sinalizados.

78 No segundo caso, destacamos a mais-valia de utilização das imagens vídeo para a reconcepção de postos de trabalho, em entrevistas de auto-confrontação, em entrevistas colectivas, ou em momentos de reflexão conjunta entre os trabalhadores, a direcção e a equipa de investigação, já que, em última análise, será do confronto entre as representações de cada um destes actores acerca do trabalho, que poderão surgir efectivas propostas de melhoria das situações analisadas.

Mas não é só a estes dois níveis de análise que se torna rico o material : é-o também no invisível, no que está para além da realidade directamente observável. Por exemplo, todas as tarefas que o trabalhador realiza diariamente, de tal forma que se tornam para si quase automáticas e difíceis de verbalizar (que se tornam visíveis recorrendo ao ralenti), podem esconder em si dificuldades importantes que urge explorar colectivamente.

Na realidade, o uso da filmagem na intervenção, possibilita aceder a elementos que podem permitir dar uma outra perspectiva sobre o trabalho (Lascaux, Manson \& Penel, 2000), já que a percepção do que está para além do observável é sempre um acrescentar de tarefas, de saberes-fazer, de modos operatórios, de estratégias mobilizadas - que devem ser integradas não só de um ponto de vista técnico, mas de reconhecimento e dignificação do trabalho realizado. 
81 Esta conclusão remete-nos directamente para uma questão inicial, já por nós abordada, que se relaciona com o modo como os resultados da captação das imagens vídeo serão realmente utilizados, a um nível formal, dentro da empresa estudada. Na verdade, é importante que da investigação resulte um produto palpável e visível, inexorável - e a filmagem tem essas características, o que faz dela simultaneamente um instrumento poderoso e perigoso.

82 Assim, a escolha das imagens para as montagens assume um papel essencial, especialmente a nível ético. É importante não esquecer, enquanto investigadores, e relembrarmo-lo aos nossos interlocutores, que a captação de imagens vídeo, ainda que realizada do modo mais directo possível, traduzirá apenas um olhar sobre um real vivido em determinado momento. A filmagem é um método, não podendo arrogar-se a substituir o real. Na verdade, existe o risco de uma interpretação imediata e causalista das imagens (especialmente por olhos não treinados e não disciplinados), que poderá pôr em causa todo o trabalho conseguido anteriormente. Como Béguin (1996) previne, as imagens são um bom suporte para evocar a acção, mas insuficientes no que toca a analisá-la: o comportamento do operador não é todo filmado. Neste sentido, é importante que o investigador se aperceba do poder da montagem que irá, nomeadamente, entregar à direcção. $\mathrm{O}$ uso do vídeo levanta questões sobre o estatuto do visível e não-visível, bem como do "mostrável" e "não-mostrável" (idem), pelo que na empresa é todo o contexto da acção que dá sentido à própria acção, e este não pode ser lido nas imagens, embora seja através delas que se tente apreendê-lo. A presença de um vídeo sobre o trabalho realizado na empresa é um "acontecimento" (Lascaux, Manson \& Penel, 2000), as imagens são inegáveis e o seu impacto não deve ser tomado de ânimo leve.

83 O processo de restituição dos dados e montagem das imagens é extremamente delicado e se reveste de susceptibilidades escondidas que importa atentar. Lascaux (2005) afirma que a formação técnica em montagem e edição de imagens é um elemento essencial para o investigador que pretende utilizar o vídeo na sua intervenção. É importante que se reconheça que a montagem resulta essencialmente de escolhas pessoais (a sucessão e selecção de imagens, de ângulos, de momentos, de silêncios...) (Baratta \& Berthet, 2000), sendo a sua organização o que determina a narrativa construída. A técnica da filmagem permite captar a situação real com toda a sua complexidade - mas não exaustividade, como lembra Falzon (1996) - e como qualquer instrumento de recolha de dados, é passível de ser enviesada. Todas as escolhas feitas pelo investigador no decurso da investigação (particularmente neste momento de selecção e montagem finais), funcionarão como filtros da situação de trabalho e por ele devem ser assumidos (idem). Assim, o objectivo final de apresentação do filme deve ser dar sentido ao conjunto de representações e situações que foram encontradas no terreno (Baratta, 1996), retratando o mais fielmente possível as interrogações que desencadearam o estudo, as reflexões, numa tentativa de levar o espectador a seguir o caminho traçado que será, sempre, único e contextualizado. A colaboração dos trabalhadores torna-se aqui essencial : o trabalho de sequenciação dos testemunhos, das imagens, das entrevistas, deve ser co-produzido entre estes e os investigadores, tornando-se elemento indispensável não só em função da garantia de confidencialidade que a estes foi dada, como também na procura de validação dos resultados do estudo. De facto, a restituição dos dados aos trabalhadores assume na démarche ergonómica uma importância central na validação dos resultados e no caso da captação de imagens em vídeo esta 
centralidade agudiza-se, torna-se parte do próprio processo de compreensão da actividade e uma acção interventiva por si mesma. Uma apresentação que reúna tanto os trabalhadores como as chefias pode suscitar múltiplas reacções e uma tomada de consciência autêntica acerca dos problemas encontrados nos postos de trabalho estudados (Lascaux, Manson \& Penel, 2000), para sobre eles se intervir.

Não existe, no entanto, nenhum instrumento que não se revista de vantagens e limitações. Ao conhecê-las podemos mais facilmente potenciá-las ou contorná-las. No caso específico da gravação em vídeo, as mais valias que possam resultar do seu uso são função da atenção atribuída às várias fases de preparação e acompanhamento da filmagem e do objectivo que sustenta a sua utilização. A observação cuidada destes factores é determinante, pois irá traduzir-se numa garantia de pertinência do seu emprego.

\section{BIBLIOGRAFIA}

Baratta, R. (1996). Image et subjectivité au travail - Donner à voir et à entendre. In Journées d'Étude Langage et Travail - Le Chercheur et le Caméra. Retirado em 15 de Junho de 2006, de http://www.langage.travail.crg.polytechnique.fr/cahiers/Cahier_8.pdf

Baratta, R., \& Berthet, M. (2000). Vidéo et intervention. Actes du XXXVéme Congrès de la SELF, France, 317-327.

Béguin, P. (1996). L'image et le caméscope. In Journées d'Étude Langage et Travail - Le Chercheur et le Caméra. Retirado em 15 de Junho de 2006, de http:// www.langage.travail.crg.polytechnique.fr/cahiers/Cahier_8.pdf

Clot, Y. \& Leplat, J. (2005). La méthode clinique en ergonomie et en psychologie du travail. Le Travail Humain, 68, 4, 289-316.

Clot, Y. (2000). La formation par l'analyse du travail : pour une troisième voie. In B. Maggi (Sous la direction). Manières de penser, manières d'agir en éducation et en formation (pp. 133-156). Paris : PUF.

Clot, Y., Faita, D., Fernandez, G., \& Scheller, L. (2000). Entretiens en autoconfrontation croisée : une méthode en clinique de l'activité [versão electrónica]. Retirado em 21 de Abril de 2006, de http://www.unites.uqam.ca/pistes/v2n1/articles/v2n1a3.htm.

Falzon, P. (1996). Travail et vídeo. In Journées d'Étude Langage et Travail - Le Chercheur et le Caméra. Retirado em 15 de Junho de 2006, de http://www.langage.travail.crg.polytechnique.fr/ cahiers/Cahier_8.pdf

Ganne, B., \& Penard, J. (1996). La recherche et le film de sociologie : une philosophie de travail. In Journées d'Étude Langage et Travail - Le Chercheur et le Caméra. Retirado em 15 de Junho de 2006, de http://www.langage.travail.crg.polytechnique.fr/cahiers/Cahier_8.pdf

Jobert, G. (2000). Dire, penser, faire. A propos de trois métaphores agissantes en formation des adultes. Education Permanente, 143, 7-28. 
Lacomblez, M. (2002, septembre). Formation et pratique de la prescription. Communication présentée à SELF. Aix-en-Provence, France.

Lacoste, M. (1996). Introduction - Filmer le travail pour l'analyser. In Journées d'Étude Langage et Travail - Le Chercheur et le Caméra. Retirado em 15 de Junho de 2006, de http:// www.langage.travail.crg.polytechnique.fr/cahiers/Cahier_8.pdf

Lallier, C. (1996). Changement à Gare du Nord - Une caméra au travail. In Journées d'Étude Langage et Travail - Le Chercheur et le Caméra. Retirado em 15 de Junho de 2006, de http:// www.langage.travail.crg.polytechnique.fr/cahiers/Cahier_8.pdf

Lascaux, C. (2005, Novembro). Comunicação pessoal. Faculdade de Psicologia e de Ciências da Educação, Universidade do Porto.

Lascaux, C., Manson, N., \& Penel, P. (2000). Place et rôle du film dans l'intervention ergonomique : pour analyser et pour transformer les situations de travail. Actes du XXXVéme Congrès de la SELF, France, 306-316.

Maggi, B. (1996). Les conceptions de la formation. Économies et Sociétés, Economie du Travail, série A B, 19, 11-12, 151-177.

Ombredane, A. \& Faverge, J-M. (1955). L'analyse du travail. Paris : PUF. Santos, M. (2004). 0 projecto de uma sociedade do conhecimento de Lev Vigotski a práticas efectivas de formação continua em Portu gal. Tese de Doutoramento, Faculdade de Psicologia e de Ciências da Educação da Universidade do Porto, Porto.

Six, B., \& Carlin, N. (1993). Ergonomie et Formation Professionnelle en Alternance - apports de l'auto-analyse ergonomique du travail. CAEN : Groupe d'intervention er de Recherche en Ergonomie et Sécurité.

Vieira, M. (2004). Autoconfrontação e análise da actividade. In M.Figueiredo, M. Athayde, J. Brito \& D. Alvarez (Org.). Labirintos do trabalho (pp. 214-237). DP\&A Editora.

\section{NOTAS}

1. Comunicação pessoal apresentada em Novembro de 2005, na Faculdade de Psicologia e de Ciências da Educação da Universidade do Porto.

2. Conservatoire National des Arts et Métiers. [3] Centre National de la Recherche Scientifique. 3. 3ème cycle de Psychologie du travail et d'Ergonomie cognitive (Direction : Pierre Rabardel)

\section{RESUMOS}

No âmbito de um seminário realizado na FPCEUP $\left.{ }^{1}\right]$, Christian Lascaux, realizador que desenvolve a sua actividade em equipas de ergonomia e de psicologia do trabalho do CNAM[ $\left.{ }^{2}\right]$, do $\left.\operatorname{CNRS}^{3}\right]$ e da Universidade de Paris 8[4], permitiu-nos adquirir outro olhar sobre a utilização do vídeo na análise da actividade : o recurso ao filme contribui não só para auxiliar a observação da situação de trabalho, como suporta o desenvolvimento de outros métodos de análise do trabalho, oferecendo uma oportunidade de confronto dos trabalhadores com as suas práticas profissionais, 
como nos demonstra o método de autoconfrontação (Clot et al., 2000).

Múltiplas questões surgem no momento de filmar: Como e quando utilizar o filme? Qual o material necessário ? Que duração deve ter a filmagem?

A resposta a estas questões integra o reconhecimento de que não é possível apresentar uma resposta única, a qual depende do contexto específico, do pedido formulado, dos objectivos subjacentes e das opções metodológicas assumidas.

En el ámbito de un seminario realizado en la FPCEUP[1], Christian Lascaux, realizador que desarrolla su actividad en equipos de ergonomía y de psicología laboral del CNAM[2], del CNRS[3] y de la Universidad de Paris 8[4], nos permitió adquirir otro punto de vista sobre el uso del vídeo en el análisis de la actividad: el recurso a la película contribuye no apenas para auxiliar la observación de la situación de trabajo, como soporta el desarrollo de otros métodos de análisis del trabajo, ofreciendo una oportunidad de enfrentamiento de los trabajadores con sus prácticas laborales, como nos demuestra el método de autoenfrentamiento (Clot et al., 2000).

Múltiplas cuestiones surgen en el momento de filmar : ¿Cómo y cuando utilizar la película? Cuál es el material necesario?

¿Cuánto debe durar la filmación?

La respuesta a estas preguntas integra el reconocimiento de que no es posible presentar una respuesta única, la cual depende del contexto específico, del pedido formulado, de los objetivos subyacentes y de las opciones metodológicas asumidas.

Dans le cadre d'un séminaire réalisé à la FPCEUP [1], Christian Lascaux, réalisateur qui développe son activité au sein d'équipes d'ergonomie et de psychologie du travail appartenants au CNAM[2], au CNRS[3] et à l'Université de Paris 8[4], nous a permit de préciser le regard que nous posions sur l'utilisation du vidéo dans l'analyse de l'activité : le recours au vidéo contribue non seulement à soutenir l'observation de la situation de travail, mais il constitue aussi un support pour le développement d'autres méthodes d'analyse du travail, offrant notamment une opportunité de confrontation des travailleurs avec leurs pratiques professionnelles, comme nous le démontre la méthode de l'autoconfrontation (Clot et al., 2000).

Plusieurs questions surgissent au moment où l'on filme : comment et quand utiliser le vidéo? Quel matériel est nécessaire? Quelle durée devra avoir la séquence?

La réponse à ces questions intègre la reconnaissance qu'il n'y a point de solution unique : elle dépendra toujours de la spécificité du contexte, de la demande formulée, des objectifs qui lui sont associés et des options méthodologiques assumées.

During a seminar that took place at FPCEUP[1], Christian Lascaux, a director that develops his activity in ergonomic and work psychology teams at CNAM[2], CNRS[3] and Paris 8 University[4], we acquired a different view of video utilisation in activity analysis : resorting to film helps not only to assist the observation of the work situation, but also supports the development of other work analysis methods, offering an opportunity for the workers being confronted with their work practices, as shown by the self-confrontation method (Clot et al. 2000). Multiple questions arise at the moment of filming : how and when to use de video ? What is the necessary material? How long should it be?

The answer to these questions integrates the recognition that it is not possible to present a unique answer, which will depend on the specific context, the request presented, the subjacent objectives and the methodological options assumed. 
ÍNDICE

Palabras claves: filmación, análisis de la actividad, autoenfrentamiento, estrategias de realización

Keywords: filming, activity analysis, self-confrontation, directing strategies

Palavras-chave: filmagem, análise da actividade, autoconfrontação, estratégias de realização

Mots-clés: filmage, analyse de l'activité, autoconfrontation, stratégies de réalisation

\section{AUTORES}

\section{LILIANA CUNHA}

Faculdade de Psicologia e de Ciências da Educação da Universidade do Porto Rua Dr. Manuel Pereira da Silva, 4200-392 Porto

lcunha@fpce.up.pt

\section{RITA GIL MATA}

Faculdade de Psicologia e de Ciências da Educação da Universidade do Porto Rua Dr. Manuel Pereira da Silva, 4200-392 Porto

rgilmata@fpce.up.pt

\section{FERNANDA CORREIA}

Faculdade de Psicologia e de Ciências da Educação da Universidade do Porto Rua Dr. Manuel Pereira da Silva, 4200-392 Porto

fcorreia@fpce.up.pt 